Previous reports on hepatic hydrothorax have used different definitions of successful pleurodesis. Radiologic evidence of recurrence is frequently observed within 2 months, even after VATS pleurodesis. ${ }^{3,5}$ Our patient is the first reported to undergo OK-432 pleurodesis that resulted in a 5-year remission. The second pleurodesis with OK432 was once again successful in terms of dramatic resolution of the recurrent hepatic hydrothorax after failure of repeated minocycline pleurodesis.

In conclusion, patients with end-stage liver cirrhosis and refractory hepatic hydrothorax have few therapeutic options. Our case demonstrates that OK-432 pleurodesis through a pigtail catheter is safe and can provide an effective alternative for patients for whom surgical intervention is not suitable.

\section{References}

1. Lazaridis KN, Frank JW, Krowka MJ, Kamath PS. Hepatic hydrothorax: pathogenesis, diagnosis, and management. Am J Med. 1999;107:262-7.
2. Milanez de Campos JR, Filho LO, de Campos Werebe E, Sette H Jr, Fernandez A Filomeno LT, et al. Thoracoscopy and talc poudrage in the management of hepatic hydrothorax. Chest. 2000;118:13-7.

3. Assouad J, Barthes Fle P, Shaker W, Souilamas R, Riquet M. Recurrent pleural effusion complicating liver cirrhosis. Ann Thorac Surg. 2003;75:986-9.

4. Takayama T, Kurokawa Y, Kaiwa Y, Ansai M, Chiba T, Inoue T, et al. A new technique of thoracoscopic pleurodesis for refractory hepatic hydrothorax. Surg Endosc. 2004;18:140-3.

5. Ferrante D, Arguedas MR, Cerfolio RJ, Collins BG, Van Leeuwen DJ. Videoassisted thoracoscopic surgery with talc pleurodesis in the management of symptomatic hepatic hydrothorax. Am J Gastroenterol. 2002;97:3172-5.

6. Luh KT, Yang PC, Kuo SH, Chang DB, Yu CJ, Lee LN. Comparison of OK-432 and mitomycin $\mathrm{C}$ pleurodesis for malignant pleural effusion caused by lung cancer. A randomized trial. Cancer. 1992;69:674-9.

7. Kishi K, Homma S, Sakamoto S, Kawabata M, Tsuboi E, Narui K, et al. High efficacy of pleurodesis using OK-432 for controlling intractable pneumothorax associated with pulmonary lymphangioleiomyomatosis. Nihon Kokyuki Gakkai Zasshi. 2003;41:704-7.

8. Nakano A, Kato M, Watanabe T, Kawai N, Ota H, Hattori T, et al. OK-432 chemical pleurodesis for the treatment of persistent chylothorax. Hepatogastroenterology. 1994;41:568-70.

9. Saito R, Rai T, Saito H, Abe K, Takahashi A, Takiguchi J, et al. Two cases of intractable hepatic hydrothorax successfully treated with nasal CPAP. Nippon Shokakibyo Gakkai Zasshi. 2006;103:1146-51.

\title{
Perioperative nesiritide and possible renal protection in patients with moderate to severe kidney dysfunction
}

\author{
Cornelius McKown Dyke, MD, ${ }^{a}$ Devinder Bhatia, MD, ${ }^{\mathrm{b}}$ Solomon Aronson, $\mathrm{MD},{ }^{\mathrm{c}}$ Nader Moazami, MD, ${ }^{\mathrm{d}}$ and Robert M. Mentzer,
} $\mathrm{Jr}, \mathrm{MD},{ }^{\mathrm{e}}$ Gastonia, NC, Houston, Tex, Durham, NC, St Louis, Mo, and Detroit, Mich

Postoperative renal dysfunction develops in approximately $5 \%$ to $30 \%$ of patients undergoing cardiac surgery with cardiopulmonary bypass, is a potent predictor of poor outcomes, and is especially prevalent among patients with preexisting renal dysfunction. ${ }^{1,2}$ Strategies to protect kidney function during cardiac surgery have included the use of low-dose dopamine, fenoldopam mesylate (INN fenoldopam), bicarbonate infusion, and diuretics, yet efficacy of any treatment has been difficult to demonstrate.

Nesiritide, a recombinant form of human B-type natriuretic peptide, has been suggested to be renally protective

\footnotetext{
From the Gaston Memorial Hospital, Gastonia, NC, ${ }^{a}$ Southeast Texas Cardiovascular, Houston, Tex, ${ }^{\mathrm{b}}$ Duke University School of Medicine, Durham, $\mathrm{NC}^{\mathrm{c}}{ }^{\mathrm{C}}$ Washington University School of Medicine, St Louis, Mo, ${ }^{\mathrm{d}}$ and Wayne State School of Medicine, Detroit, Mich.

Statistical analysis and sponsorship of the NAPA trial was provided by Scios Inc, Mountain View, Calif.

Received for publication Oct 15, 2007; accepted for publication Dec 2, 2007.

Address for reprints: Cornelius McKown Dyke, MD, Gaston Memorial Hospital, 2555

Court Dr, Suite 200, Gastonia, NC 28056.

J Thorac Cardiovasc Surg 2008;136:1369-70

$0022-5223 / \$ 34.00$

Copyright $(c) 2008$ by The American Association for Thoracic Surgery

doi:10.1016/j.jtcvs.2007.12.079
}

for patients with end-stage heart failure. ${ }^{3}$ Additionally, in the exploratory Nesiritide Administered Peri-Anesthesia (NAPA) trial, patients with congestive heart failure undergoing cardiac surgery who received nesiritide had a significantly lower incidence of postoperative renal dysfunction. ${ }^{4}$ The goal of this post hoc evaluation of the NAPA trial was to assess the impact of perioperative nesiritide on patients with preexisting, non-hemodialysis dependent, moderateto-severe renal dysfunction.

\section{MATERIALS AND METHODS}

The design and methodology of the NAPA trial has been reported previously. ${ }^{4}$ In brief, patients with chronic left ventricular dysfunction underwent cardiac surgery utilizing cardiopulmonary bypass. Patients were randomly assigned to treatment with intravenous infusion of nesiritide $(0.01 \mu \mathrm{g} /[\mathrm{kg} \cdot \mathrm{min}]$ without bolus) or placebo in addition to usual care. Study drug infusion was initiated after induction of anesthesia and continued for 24 to 96 hours after surgery. Inotropes and vasopressor medications were used without restriction in accordance with institutional practice. In the NAPA trial, 303 patients were randomly assigned, of whom 272 (nesiritide $\mathrm{n}=137$, placebo $\mathrm{n}=135$ ) ultimately underwent surgery. Of these 272 patients, 266 (nesiritide $n=133$, placebo $n=133$ ) had a baseline serum creatinine measurement and at least one postoperative serum creatinine measurement, and these patients form the basis for this evaluation. 


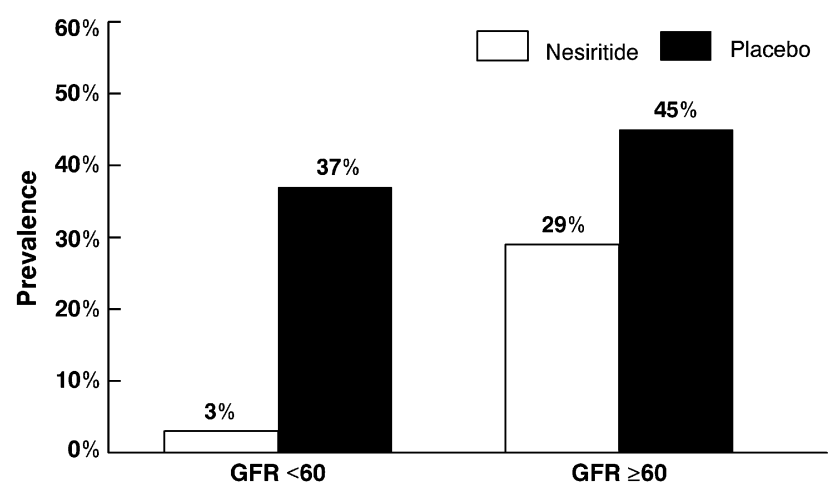

GFR $\geq 60$ : no to mild renal dysfunction GFR <60: moderate to severe renal dysfunction *an increase in SCr $>0.5 \mathrm{mg} / \mathrm{dL}$ or a decrease in GFR $>25 \%$ of baseline

FIGURE 1. Postoperative renal dysfunction was significantly reduced among patients who received nesiritide, with protective effect especially evident in patients with preexisting moderate-to-severe renal dysfunction. $G F R$, Glomerular filtration rate; $S C r$, serum creatinine.

Preexisting renal dysfunction was defined on the basis of the estimated glomerular filtration rate (GFR), as calculated by the Modification of Diet in Renal Disease trial equation. The impacts of nesiritide infusion on patients with moderate-to-severe renal dysfunction (estimated GFR 60 $\mathrm{mL} / \mathrm{min}$ ) and mild-to-no renal dysfunction (estimated GFR $\geq 60 \mathrm{~mL} / \mathrm{min}$ ) were assessed.

Because no standard definition for postoperative renal dysfunction exists, we quantified renal dysfunction after surgery in two ways, as a greater than $0.5-\mathrm{mg} / \mathrm{dL}$ increase in serum creatinine or as a greater than $25 \%$ decrease in GFR through hospital discharge or study day 14. The prevalences of postoperative renal dysfunction in the two treatment groups were compared with the Fisher exact test. The relative risk reduction was analyzed, and the corresponding 95\% confidence intervals and $P$ values were based on Mantel-Haenszel statistics with SAS 8.2 software (SAS Institute, Inc, Cary, NC). Unless otherwise noted, summary statistics for continuous variables are presented as mean $\pm \mathrm{SD}$.

\section{RESULTS}

Patient characteristics and procedures performed have been previously detailed. ${ }^{4}$ Most patients underwent isolated coronary artery bypass grafting. Mean left ventricular ejection fraction at baseline was $30 \% \pm 7 \%$. The mean duration of study drug infusion was similar between groups (nesiritide $39 \pm 22$ hours, placebo $41 \pm 23$ hours). Adjunct pharmacologic therapy was also similar between groups. ${ }^{4}$

The incidence of postoperative renal dysfunction was significantly reduced for all patients who received nesiritide, but this protective effect was especially evident in looking at the patients with preexisting moderate-to-severe renal dysfunction (Figure 1). Perioperative administration of nesiritide reduced the risk of an acute postoperative increase in serum creatinine of more than $0.5 \mathrm{mg} / \mathrm{dL}$ or an acute postoperative decrease in GRF of more than $25 \%$ of baseline by $90 \%$ (95\% confidence interval $33 \%-$
$99 \%, P=.001)$ in patients with moderate-to-severe preexisting renal dysfunction.

\section{DISCUSSION}

The NAPA study was a phase 2 exploratory study that enrolled patients with left ventricular dysfunction undergoing on-pump coronary bypass grafting with or without mitral valve surgery. Nesiritide was associated with attenuation of the increases in postoperative serum creatinine observed in the control group. Whether nesiritide was associated with renal protection in patients with preexisting renal dysfunction was less clear. In the previous NAPA report, preexisting renal dysfunction was prospectively defined as a baseline serum creatinine greater than $1.2 \mathrm{mg} / \mathrm{dL}$. ${ }^{4}$ The use of serum creatinine as a definition of renal dysfunction is questionable, however, because other factors influence serum creatinine levels, including creatinine generation and secretion. In this reanalysis with a stricter definition of renal failure, the greatest benefit of nesiritide infusion was seen in patients with preexisting moderate to severe renal dysfunction. In this high-risk population, reducing the risk of postoperative renal dysfunction may have contributed to the shorter hospital stay and reduced mortality observed with nesiritide treatment. ${ }^{4}$

There are several limitations to this report. This analysis was a post hoc evaluation of the NAPA trial and thus not prospectively powered to evaluate the effect of nesiritide on postoperative renal dysfunction in patients with preexisting renal disease. The use of estimated GFR in this analysis, however, is a more appropriate definition of renal failure than is change in serum creatinine alone. We consider the data suggesting that nesiritide may be renally protective in this high-risk population to be provocative. Further evaluation of the perioperative use of nesiritide to prevent renal dysfunction after cardiac surgery is warranted.

\section{References}

1. Loef BG, Epema AH, Smilde TD, Jennings RH, Ebels T, Navis G, et al. Immediate postoperative renal function deterioration in cardiac surgical patients predicts in-hospital mortality and long-term survival. J Am Soc Nephrol. 2005; 16:195-200.

2. Chonchol MB, Aboyans V, Lacroix P, Smits G, Berl T, Laskar M. Long-term outcomes after coronary artery bypass grafting: preoperative kidney function is prognostic. J Thorac Cardiovasc Surg. 2007;134:683-9.

3. Zierer A, Voeller AK, Melby SJ, Kawa CB, Guthrie TJ, Baumgartner M, et al. Potential renal protective benefits of intra-operative BNP infusion during cardiac transplantation. Transplant Proc. 2006;38:3680-4.

4. Mentzer RM, Oz M, Sladen RN, Graev AH, Hebeler RF Jr, Luber JM Jr, et al. Effects of perioperative nesiritide in patients with left ventricular dysfunction undergoing cardiac surgery: the NAPA trial. J Am Coll Cardiol. 2007;49: 716-21. 